\title{
Translational outcomes relevant to neurodevelopmental disorders following early life exposure of rats to chlorpyrifos
}

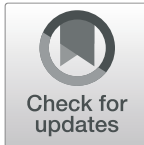

Elizabeth L. Berg' ${ }^{1}$, Tianna M. Ching ${ }^{1}$, Donald A. Bruun² ${ }^{2}$ Josef K. Rivera ${ }^{1}$, Milo Careaga ${ }^{1}$, Jacob Ellegood ${ }^{3}$, Jason P. Lerch ${ }^{3,4}$, Markus Wöhr ${ }^{5,6}$, Pamela J. Lein ${ }^{2}$ and Jill L. Silverman ${ }^{1 *}$ (D)

\begin{abstract}
Background: Neurodevelopmental disorders (NDDs), including intellectual disability, attention deficit hyperactivity disorder (ADHD), and autism spectrum disorder (ASD), are pervasive, lifelong disorders for which pharmacological interventions are not readily available. Substantial increases in the prevalence of NDDs over a relatively short period may not be attributed solely to genetic factors and/or improved diagnostic criteria. There is now a consensus that multiple genetic loci combined with environmental risk factors during critical periods of neurodevelopment influence NDD susceptibility and symptom severity. Organophosphorus (OP) pesticides have been identified as potential environmental risk factors. Epidemiological studies suggest that children exposed prenatally to the OP pesticide chlorpyrifos (CPF) have significant mental and motor delays and strong positive associations for the development of a clinical diagnosis of intellectual delay or disability, ADHD, or ASD.
\end{abstract}

Methods: We tested the hypothesis that developmental CPF exposure impairs behavior relevant to NDD phenotypes (i.e., deficits in social communication and repetitive, restricted behavior). Male and female rat pups were exposed to CPF at 0.1, 0.3 , or $1.0 \mathrm{mg} / \mathrm{kg}$ (s.c.) from postnatal days $1-4$.

Results: These CPF doses did not significantly inhibit acetylcholinesterase activity in the blood or brain but significantly impaired pup ultrasonic vocalizations (USV) in both sexes. Social communication in juveniles via positive affiliative 50-kHz USV playback was absent in females exposed to CPF at $0.3 \mathrm{mg} / \mathrm{kg}$ and $1.0 \mathrm{mg} / \mathrm{kg}$. In contrast, this CPF exposure paradigm had no significant effect on gross locomotor abilities or contextual and cued fear memory. Ex vivo magnetic resonance imaging largely found no differences between the CPF-exposed rats and the corresponding vehicle controls using strict false discovery correction; however, there were interesting trends in females in the $0.3 \mathrm{mg} / \mathrm{kg}$ dose group.

Conclusions: This work generated and characterized a rat model of developmental CPF exposure that exhibits adverse behavioral phenotypes resulting from perinatal exposures at levels that did not significantly inhibit acetylcholinesterase activity in the brain or blood. These data suggest that current regulations regarding safe levels of CPF need to be reconsidered.

Keywords: Animal models, Behavior, Autism, Neurodevelopment, Toxicology, Pesticides, Chlorpyrifos, Imaging, Social, Rat, Vocalization, USV

\footnotetext{
* Correspondence: jsilverman@ucdavis.edu

${ }^{1}$ MIND Institute and Department of Psychiatry and Behavioral Sciences,

University of California Davis School of Medicine, Sacramento, CA, USA

Full list of author information is available at the end of the article
}

C The Author(s). 2020 Open Access This article is licensed under a Creative Commons Attribution 4.0 International License, which permits use, sharing, adaptation, distribution and reproduction in any medium or format, as long as you give appropriate credit to the original author(s) and the source, provide a link to the Creative Commons licence, and indicate if changes were made. The images or other third party material in this article are included in the article's Creative Commons licence, unless indicated otherwise in a credit line to the material. If material is not included in the article's Creative Commons licence and your intended use is not permitted by statutory regulation or exceeds the permitted use, you will need to obtain permission directly from the copyright holder. To view a copy of this licence, visit http://creativecommons.org/licenses/by/4.0/ The Creative Commons Public Domain Dedication waiver (http://creativecommons.org/publicdomain/zero/1.0/) applies to the data made available in this article, unless otherwise stated in a credit line to the data. 


\section{Background}

The wide use of insecticides has raised a significant concern due to possible health effects associated with exposure to these compounds [1-5]. Insecticides are used globally to control crop pests in agriculture, to reduce household pests, to reduce insect damage to lawns and golf courses, and as mosquito control agents [6-8]. Among the most widely used insecticides are the organophosphorus pesticides (OPs), which include chlorpyrifos, parathion, and diazinon $[9,10]$. Prenatal exposure to OPs has been associated with abnormal psychomotor ability, deficits in working memory and intelligence quotient, and disrupted behaviors in children [8, 11-18]. Experimental studies have also demonstrated an association between prenatal exposure to OPs and abnormal developmental reflexes [19].

The most extensively studied OP pesticide to date with respect to neurodevelopmental insults has been chlorpyrifos (CPF). Eaton and colleagues published a comprehensive review that examined the large body of toxicological data and epidemiological information describing effects of CPF in humans, with an emphasis on its controversial adverse effects on neurodevelopment [7]. Subsequently, the UC Davis Childhood Autism Risks from Genetics and Environment (CHARGE) study [8, 18] reported significant associations between prenatal OP exposures and mental and motor delays and an increased risk of autism spectrum disorder (ASD). Studies of a separate cohort of children in New York City provided corroborating behavioral data and brain structural neuroimaging of children prenatally exposed to CPF, illustrating enlargement of various cortical regions and effects on underlying white matter [20]. A recent metaanalysis of the epidemiological data concluded that there is a positive association between CPF and neurodevelopmental disorders, which warranted further investigation of CPF developmental neurotoxicity [21].

Rodents exposed to relatively high, but subtoxic, doses of CPF during early life exhibit delayed development of psychomotor reflexes $[22,23]$, sexual-social behaviors [24, 25], and impaired cognitive performance [26-29] later in life. But whether developmental exposure to CPF at levels that do not significantly inhibit acetylcholinesterase (AChE) causes phenotypes of relevance to neurodevelopmental disorders remains unclear. The goal of this study was to generate and use a rat model of developmental exposure to CPF to study the effect of environmentally relevant levels of CPF on a range of behaviors in young animals, including social communication, Pavlovian learning and memory, anatomical phenotypes determined by magnetic resonance imaging, and sexually dimorphic effects on these outcomes. The exposure paradigm used in this study was based on the finding from the CHARGE study which showed that pesticides had the most significant effect on health outcomes when exposure occurred during the third trimester $[8,18]$.

Characterizing the developmental neurotoxicity of environmentally relevant $\mathrm{CPF}$ exposures is required for assessing the risk that CPF poses to the developing brain, and for developing policies to protect the developing brain from this risk. In 2017, the federal EPA administrator denied a widespread petition to ban $\mathrm{CPF}$, which is currently being appealed and battled in litigation. Additionally, the California Department of Pesticide Regulation announced in early 2019 that it will cancel the registration that currently allows chlorpyrifos to be sold in California. Thus, we aimed to use our preclinical model system to further clarify links between CPF exposure and adverse neurodevelopmental outcomes. This knowledge of CPF developmental neurotoxicity is crucial for implementing protective policies and mechanisms for estimating whether low dose exposures, via food and water consumption, pose real threats to human health.

\section{Methods \\ Materials}

Chlorpyrifos (CPF; o,o-diethyl [o-3,5,6-trichloro-2-pyridinol] phosphorothionate; $99.5 \%$ purity) was purchased from Chem Service (West Chester, PA, USA) and used within 6 months of purchase with interim storage as recommended by the manufacturer. Solutions were made weekly in $\mathrm{NEOBEE}^{\oplus} \mathrm{M}-5$ oil vehicle (Spectrum Chemical, Gardena, CA, USA) at their final concentrations and stored in a polypropylene container in the dark at room temperature.

\section{Subjects}

Male and female Sprague-Dawley rats were purchased from Envigo (Indianapolis, Indiana) to generate cohorts for testing. All procedures were approved by the Institutional Animal Care and Use Committee (IACUC) at the University of California Davis and were conducted in accordance with the National Institutes of Health Guide for the Care and Use of Laboratory Animals. All animals were housed in a temperature-controlled vivarium maintained on a 12:12 light-dark cycle. OP pesticides were not applied in the vivarium before or during the study. To identify individual subjects, pups were labeled on the back via permanent marker on postnatal day 1 , which was reapplied daily. As fur developed, animals were identified via tail marks, which were coded to allow investigators to run and score behaviors blind to the experimental group.

\section{Cohorts}

One cohort of rats, which consisted of 58 rat pups from 9 litters, was tested for early life communication. Rat pups were exposed daily to CPF (1.0 or $3.0 \mathrm{mg} / \mathrm{kg}$ ) or vehicle (Neobee Coconut Oil; Spectrum Chemical MFG Corp) via 
s.c. injection $(2 \mathrm{~mL} / \mathrm{kg})$ with a 30 gauge Hamilton syringe on postnatal day (PND) 1-4. On PND 8, pups underwent isolation-induced ultrasonic vocalization (USV) collection. These data, summarized in Supplementary Fig. S1, were the basis for the decision to test doses lower than $1.0 \mathrm{mg} /$ $\mathrm{kg}$ in a second cohort.

A second cohort of rats, which consisted of 2 males and 2 females from each of 25 litters, was analyzed for early life and juvenile behavioral effects as well as juvenile neuroanatomical effects of CPF exposure. Rat pups were exposed daily to CPF at $0.1,0.3$, or $1.0 \mathrm{mg} / \mathrm{kg}$ or to an equal volume of vehicle (Neobee Coconut Oil; Spectrum Chemical MFG Corp) via s.c. injection $(2 \mathrm{~mL} /$ $\mathrm{kg}$ ) with a 30 gauge Hamilton syringe on PND 1-4. Litters were reduced to 8 pups ( $4 \mathrm{~m}$ and $4 \mathrm{f}$ when possible) on PND 4, at which time, the culled littermates of the behavioral subjects were analyzed for acetylcholinesterase (AChE) activity in brain and blood at $1 \mathrm{~h}$ postinjection. The behavioral battery consisted of pup ultrasonic vocalizations and developmental milestones on PND 8, 12, and 16, locomotion in an open field, response to USV playback, and cued and contextual fear conditioning. After behavioral testing, brains were harvested and fixed for MRI analysis.

\section{Behavioral assays \\ Isolation-induced pup $40-\mathrm{kHz}$ ultrasonic vocalizations}

During the first few weeks of life, rodent pups emit ultrasonic vocalizations (USV) when separated from their mother and litter [30-32]. On PND 8, 12, and 16 pups were individually removed from the nest in a random order and placed into an open-top plastic isolation container containing corncob bedding. USV were collected for 3 min with an ultrasonic microphone (Avisoft Bioacoustics, Glienicke, Germany) using methods outlined previously [33, 34]. Immediately following USV collection, body temperature and body weight were measured.

\section{Open field locomotion}

Sedation or hyperactivity may have confounding effects on assays of sociability. Therefore, on PND 19, exploratory activity in a novel open field was automatically measured for $30 \mathrm{~min}$ as described previously [33, 34].

\section{USV playback}

Behavioral responses to playback of $50-\mathrm{kHz}$ ultrasonic vocalizations were measured on PND 24-27 as previously described [34]. Briefly, rats were placed individually on an 8-arm elevated radial maze and presented with pro-social $50-\mathrm{kHz}$ USV and a time- and amplitudematched white noise acoustic stimulus control using an ultrasonic speaker (Avisoft Bioacoustics, Glienicke, Germany). Social exploratory and approach behavior in response to the USV were assessed, as was the behavioral response to the white noise stimulus.

\section{Cued and contextual fear conditioning}

Learning and memory were assessed on PND 30-33 using a previously described 3-day cued and contextual fear conditioning assay [35]. On day one, rats were trained to associate a foot shock with a specific environmental context as well as with a white noise auditory cue using automated chambers (Med Associates, Inc., St. Albans, Vermont). Approximately $24 \mathrm{~h}$ later, rats were re-exposed to the same context without the auditory cue and time spent freezing was quantified to assess contextual fear memory. Approximately $48 \mathrm{~h}$ following the initial training, rats were re-exposed to the auditory cue in a novel environmental context and time spent freezing was quantified to assess cued fear memory.

\section{Ex vivo neuroimaging via magnetic resonance imaging}

On PND 35-36, brains were flushed via transcardial perfusion (flow rate of $2 \mathrm{~mL} / \mathrm{min}$ ) with $50 \mathrm{~mL}$ phosphatebuffered saline (PBS) containing $10 \mathrm{U} / \mathrm{mL}$ heparin and 2 $\mathrm{mM}$ ProHance (a gadolinium-based contrast agent; Bracco Diagnostics Inc.), fixed with $50 \mathrm{~mL} 4 \%$ paraformaldehyde (PFA) in PBS containing $2 \mathrm{mM}$ ProHance, and collected for neuroimaging following previously published protocols [36]. Following perfusion, brains were incubated in the $4 \%$ PFA solution for $24 \mathrm{~h}$ at $4{ }^{\circ} \mathrm{C}$ then transferred to a storage PBS solution containing $0.02 \%$ sodium azide. Brains were incubated in the storage solution at $4{ }^{\circ} \mathrm{C}$ for at least 1 month prior to scanning. Images were acquired and analyzed following a protocol previously described [33, 37]. Multiple comparisons were controlled for using the false discovery rate (FDR) with the significance level for the FDR-adjusted $p$ value $(q)$ set at $q<0.05$ [38].

\section{AChE activity assay}

One hour following the final CPF dosing on PND 4, pups were euthanized by decapitation and blood was collected by cardiac puncture into tubes containing EDTA as an anti-coagulant (Becton-Dickinson, Franklin Lakes, NJ). Blood was diluted 1:25 with phosphate buffer with $0.03 \%$ Triton X-100 (Fisher Scientific, Pittsburg, PA), vortexed, and snap frozen for later analysis. Brains were collected and snap frozen for later analysis. For the AChE activity assay, brain tissue was thawed on ice, homogenized in phosphate buffer with $1 \%$ Triton X-100, and AChE activity quantified using the standard Ellman Assay [39] with 5,5'-dithio-bis-2-nitrobenzoic acid (DTMB) and acetylthiocholine iodide (ASChI) as the substrates (Sigma-Aldrich, St. Louis, MO). Tetraisopropyl pyrophosphoramide (Sigma) was included to inhibit pseudocholinesterase. Blood AChE activity was 
normalized to hemoglobin levels, which were determined using a StanBio Laboratory Stat-Site M hemoglobin meter and test strips (Boerne, TX, USA). Brain AChE activity was normalized to protein concentration as determined using the BCA assay kit (Pierce, Rockford, IL).

\section{Statistical analyses}

Developmental vocalizations, temperature, weight, and open field metrics were analyzed via repeated measures ANOVA with dose as the between-group factor and time as the within-group factor. Following detection of a significant main effect and/or time by dose interaction, post hoc testing was carried out using Holm-Sidak's multiple comparisons test. Paired $t$ tests (one per dose group) were used to compare time spent on the proximal and distal arms during the USV playback paradigm and locomotion during the playback test was compared using repeated measures or one-way ANOVA. Comparisons between freezing times were carried out for each test phase with one-way ANOVA. Acetylcholinesterase activity was analyzed using one-way ANOVA. Data were analyzed via GraphPad Prism. All significance levels were set at $p<0.05$ and all $t$ tests were two tailed. Multiple comparisons were corrected for via post hoc testing using Holm-Sidak's multiple comparisons test.

\section{Results}

Developmental CPF exposure reduced isolation-induced pup ultrasonic vocalizations

Pup ultrasonic vocalizations (USV) of infant rats measure an early communicative behavior between pups and mother. Isolation-induced USV were collected for $3 \mathrm{~min}$ as social communication signals in rat pups, as previously described [33]. CPF-exposed pups emitted significantly fewer USV across early development (Fig. 1a (males) $F_{(2,90)}=286.5, p<0.001$; Fig. $1 \mathrm{~b}$ (females) $F_{(2 \text {, }}$ $90)=267.7, p<0.001)$. As pups grow, they learn to temperature regulate, open their eyes, and are less reliant on maternal care, which is why USV decrease in number over developmental days. There was a significant main effect of experimental group on USV emission $\left(F_{\text {males }}(3,45)=3.048, p<0.05\right)$. Holm-Sidak post hoc analysis corrected for multiple comparisons highlighted significant differences on PND 12, when fewer USV were emitted in the $1.0 \mathrm{mg} / \mathrm{kg}$ CPF-exposed male pups, and on PND 16 in all CPF dose groups compared to vehicle. CPF-exposed female pups also emitted significantly fewer $\operatorname{USV}\left(F_{(3,37)}=2.949, p<0.05\right)$. Holm-Sidak post hoc analysis highlighted strong trending differences on PND 8 , as fewer USV were emitted in the $0.3 \mathrm{mg} / \mathrm{kg}$ CPF-exposed female pups $(p=0.061)$, and significant differences at PND 12 and 16 in the $0.3 \mathrm{mg} / \mathrm{kg}$ CPFexposed female pups compared to vehicle.
Body weight and temperature were also collected to assure the reduced USV were not the result of being physically smaller as body weight is known to alter pup USV emission [30, 31]. Body temperature did not differ between CPF exposure groups and vehicle (Fig. 1c (males) $F_{(3,46)}=0.5381, p>0.05$; Fig. $1 \mathrm{~d}$ (females) $F_{(3,}$, 46) $=0.67, p>0.05)$. Weight did not differ between CPF exposure groups and vehicle (Fig. 1e (males) $F_{(3,46)}=$ $0.2745, p>0.05$; Fig. If (females) $F_{(3,46)}=0.5234, p>$ $0.05)$, indicating typical growth and ability to thrive. In addition to being important control metrics for the pup USV assay, the observation that overall growth and health was not impacted by CPF exposure confirms the lack of systemic toxicity that has been reported with higher CPF doses using a functional observation battery $[40,41]$.

Analysis of typical early neurological reflexes did not reveal any significant differences between CPF-exposed pups and vehicle controls (Supplementary Fig. S2). Specifically, there were no significant differences between exposure groups in latencies to navigate upright in negative geotaxis and circle traverse, simple metrics for motoric, postural, and proprioceptive processes that underlie the ability of infant rodents to navigate on an inclined plane or to the outer rim from the center of circle (Fig. S2A (males) $F_{(3,46)}=0.4776, p>0.05$; Fig. S2B (females) $F_{(3,46)}=1.098, p>0.05$; Fig. S2C (males) $F_{(3,}$ 46) $=1.224, p>0.05$; Fig. S2D (females) $F_{(3,46)}=1.1319$, $p>0.05)$.

\section{Normal locomotion and exploratory activity following developmental CPF exposure}

Normal motor function following early life exposure to low doses of CPF was confirmed by lack of an effect of $\mathrm{CPF}$ on motor abilities in the open field exploratory locomotion task across a 30-min session. No CPF effect was observed in activity metrics of horizontal activity (Fig. 2a (males) $F_{(3,46)}=0.2303, p>0.05$; Fig. 2b (females) $F_{(3,46)}$ $=0.3341, p>0.05$ ), vertical activity (Fig. $2 \mathrm{c}$ (males) $F_{(3,46)}$ $=0.2278, p>0.05$; Fig. $2 \mathrm{~d}$ (females) $F_{(3,46)}=0.2562, p>$ 0.05 ), or time spent in the center of the arena (Fig. $2 \mathrm{e}$ (males) $F_{(3,46)}=0.7749, p>0.05$; Fig. $2 \mathrm{f}$ (females) $F_{(3,46)}=$ 2.150, $p>0.05)$.

\section{Reduced social exploration to affiliative $50-\mathrm{kHz}$ ultrasonic} calls (USV) in female CPF-exposed juveniles

Social exploratory behavior displayed by the male (Fig. 3c $\left.t_{(1,13)}=3.576, p<0.005\right)$ and female vehicle control groups (Fig. 3d $t_{(1,13)}=3.509, p<0.005$ ) was directed toward playback of pro-social $50-\mathrm{kHz}$ USV, as reflected in the parameter of time spent on the arms proximal to the sound source emitting $50-\mathrm{kHz}$ USV as compared to the distal arms of the radial maze. All groups of male 


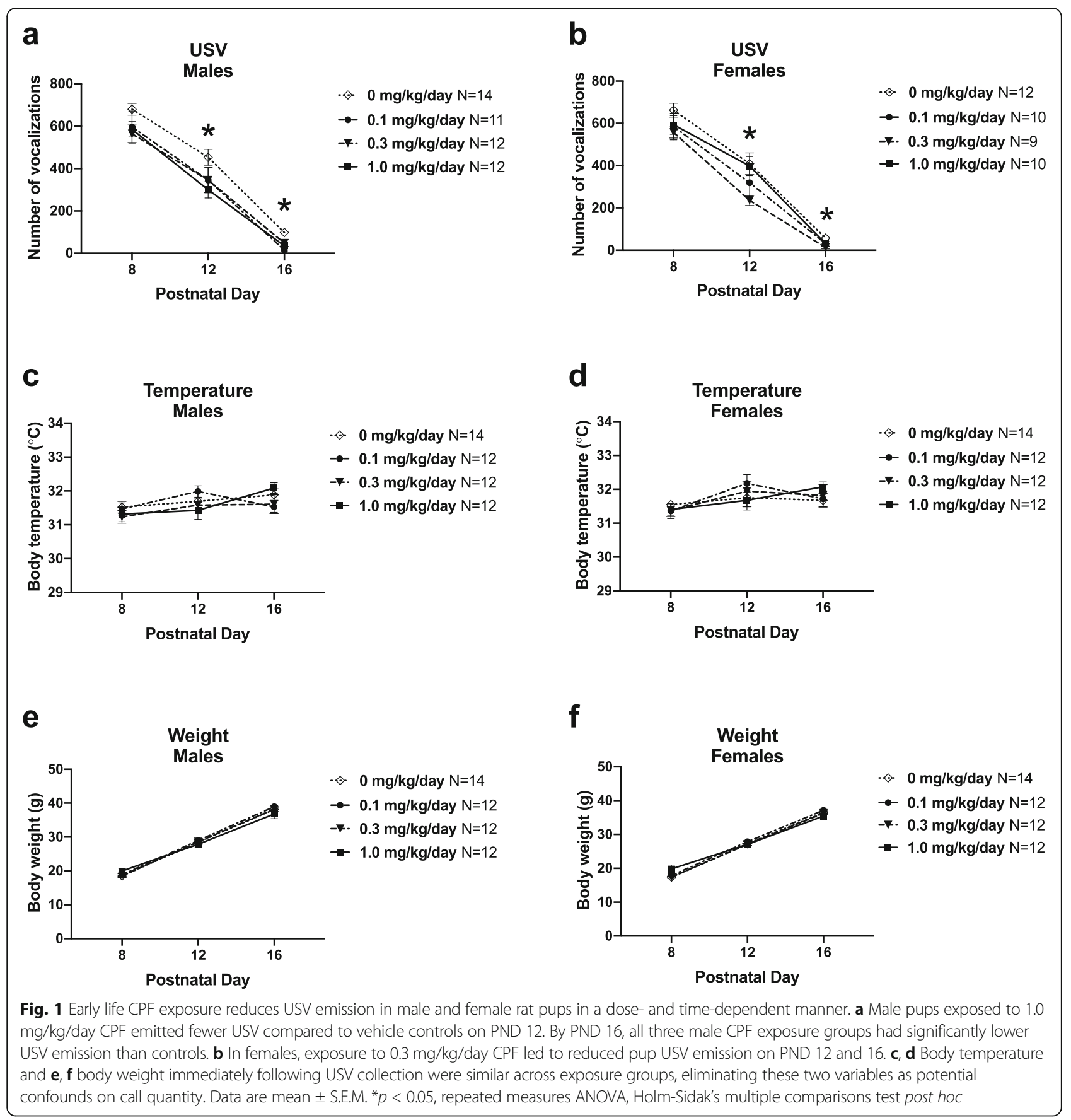

juvenile rats (vehicle and each dose of CPF) spent significantly longer on the arms proximal to the speaker emitting the $50-\mathrm{kHz}$ USV upon playback (Fig. 3c (0.1 dose) $t_{(1,13)}=2.738, p<0.02$; Fig. $3 \mathrm{c}(0.3$ dose $) t_{(1,13)}=$ 4.587, $p<0.001$; Fig. 3c (1.0 dose) $t_{(1,13)}=4.502$, $p<0.001)$. In contrast, the $0.3 \mathrm{mg} / \mathrm{kg}$ and $1.0 \mathrm{mg} / \mathrm{kg}$ CPF-exposed females rats did not spend significantly more time on the proximal arms (Fig. $3 \mathrm{~d}$ (0.1 dose) $t_{(1 \text {, }}$ 13) $=3.001, p<0.005$; Fig. $3 \mathrm{~d}(0.3$ dose $) t_{(1,13)}=1.373$, $p>0.05$; Fig. 3d (1.0 dose) $\left.t_{(1,13)}=0.7127, p>0.05\right)$.
All groups demonstrated a similar locomotor response to the $50-\mathrm{kHz}$ USV, characterized by elevated movement during the USV as compared to baseline (Fig. 3e (males, time) $F_{(1,46)}=100.5, p<0.0001$; Fig. $3 \mathrm{e}$ (males, group) $F_{(3,46)}=0.337, p>0.05$; Fig. 3e (males, time $\mathrm{x}$ group) $F_{(3,46)}=0.533, p>0.05$; Fig. 3f (females, time) $F_{(1,46)}$ $=45.90, p<0.0001$; Fig. 3f (females, group) $F_{(3,46)}=$ $0.379, p>0.05$; Fig. $3 \mathrm{f}$ (females, time $\mathrm{x}$ group) $F_{(3,46)}=$ $0.682, p>0.05)$. Distance traveled in response to the white noise control stimulus did not differ between 


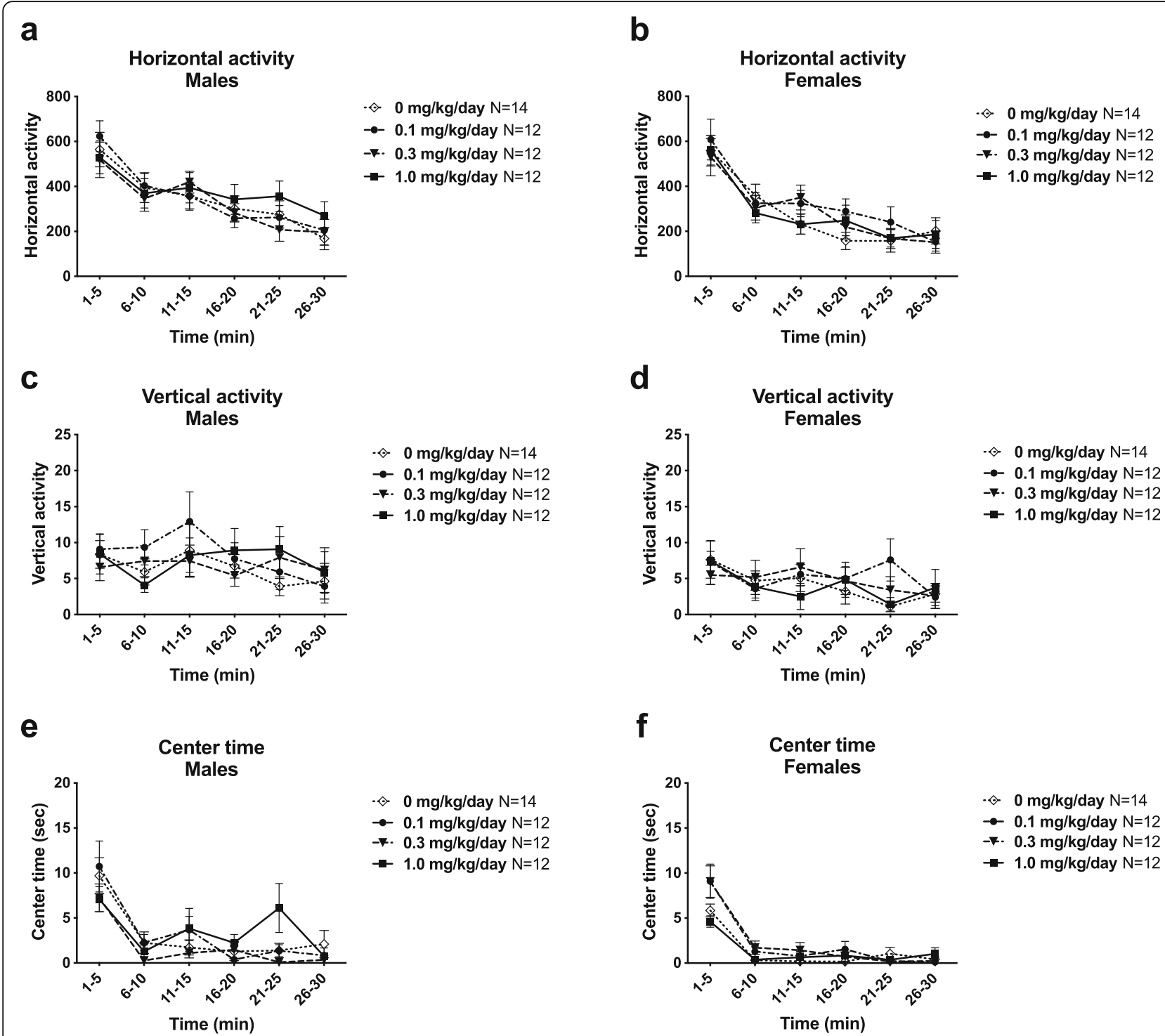

Fig. 2 Early life exposure to CPF did not affect gross locomotor abilities. Both male and female rats of all exposure groups exhibited normal levels of $(\mathbf{a}, \mathbf{b})$ horizontal activity, $(\mathbf{c}, \mathbf{d})$ vertical activity, and $(\mathbf{e}, \mathbf{f})$ center time on PND 19. Data are mean \pm S.E.M

exposure groups, and all groups exhibited comparable levels of locomotion before (Fig. $3 \mathrm{~g}$ (males) $F_{(3,46)}=$ 0.707, $p>0.05$; Fig. 3h (females) $F_{(3,46)}=0.448, p>$ $0.05)$ and during the noise stimulus (Fig. $3 g$ (males) $F_{(3}$, 46) $=1.094, p>0.05$; Fig. 3h (females) $F_{(3,46)}=1.596, p$ $>0.05)$. These findings rule out the possibility of a confounding hearing deficit in the CPF-exposed groups.

\section{CPF-exposed rats demonstrated intact contextual and cued fear memory}

Learning and memory was evaluated using two measures of Pavlovian fear conditioning with a $24 \mathrm{~h}$ contextual component and a $48 \mathrm{~h}$ tone cued fear conditioning. High levels of freezing were observed subsequent to the conditioned stimulus (CS) - unconditioned stimulus (UCS) pairings on the training day, in both exposed groups (Fig. 4a (males) no group difference in post-training freeze scores, $F_{(3,46)}=0.3342, p>0.05$; Fig. $4 \mathrm{~b}$ (females) no group difference in post-training freeze scores, $F_{(3,46)}$ $=0.2033, p>0.05$ ), indicating no confounds and no deficits in the learning of the associations between the context stimuli and tone cues. No exposure group difference in freezing was observed $24 \mathrm{~h}$ following CSUCS training (Fig. 4c (males) $F_{(3,46)}=0.02571, p>0.05$; Fig. 4d (females) $\left.F_{(3,46)}=0.2045, p>0.05\right)$ when placed in the context chamber from conditioning training with identical stimulus cues. Levels of freezing, pre- and postcue presentation $48 \mathrm{~h}$ after training, showed no effect of exposure (Fig. 4e (males, pre-cue) $F_{(3,46)}=0.1365, p>$ 0.05; Fig. 4e (males, cue) $F_{(3,46)}=0.6103, p>0.05$; Fig. 4f 

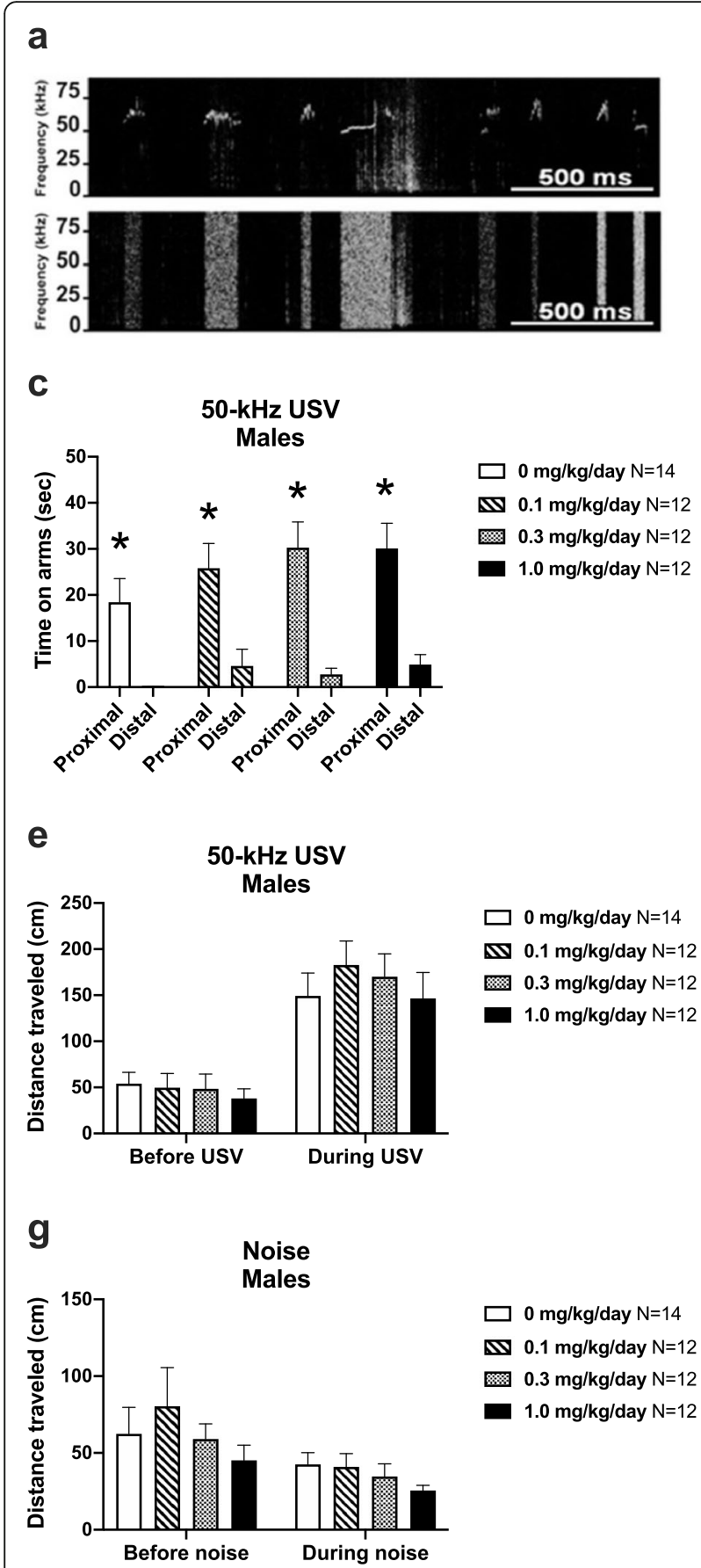

ه $0.1 \mathrm{mg} / \mathrm{kg} /$ day $\mathrm{N}=12$

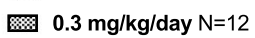

$1.0 \mathrm{mg} / \mathrm{kg} /$ day $\mathrm{N}=12$ b

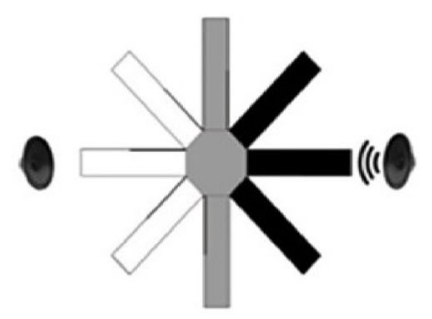

d

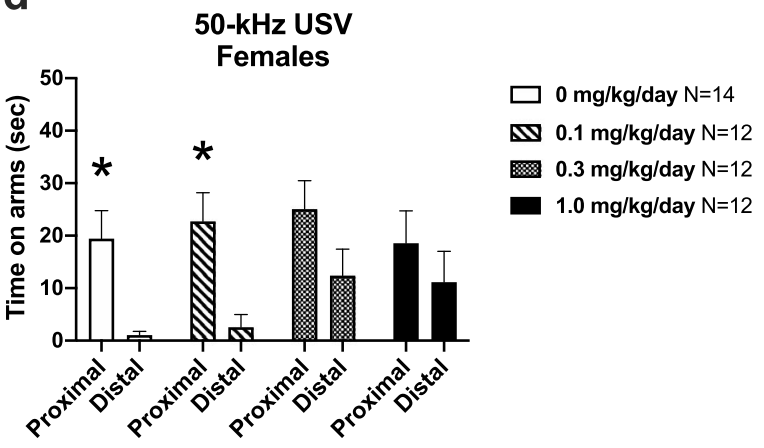

f

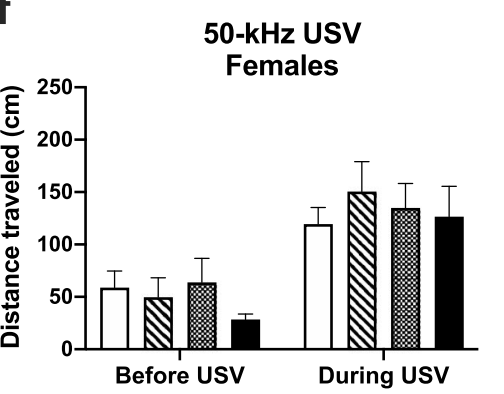

$\square 0 \mathrm{mg} / \mathrm{kg} /$ day $\mathrm{N}=14$ NV $0.1 \mathrm{mg} / \mathrm{kg} /$ day $\mathrm{N}=12$ $0.3 \mathrm{mg} / \mathrm{kg} / \mathrm{day} \mathrm{N}=12$ $1.0 \mathrm{mg} / \mathrm{kg} /$ day $\mathrm{N}=12$

h

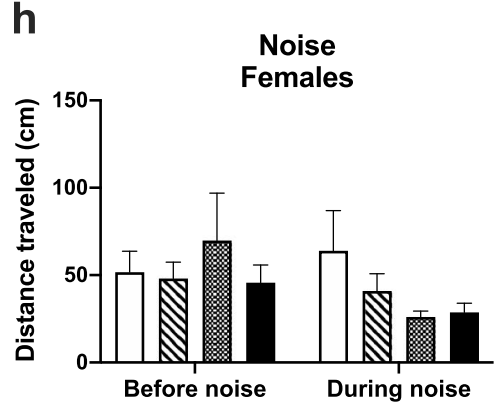

$\square 0 \mathrm{mg} / \mathrm{kg} /$ day $\mathrm{N}=14$ $\mathbf{\$} 0.1 \mathrm{mg} / \mathrm{kg} / \mathrm{day} \mathrm{N}=12$ $0.3 \mathrm{mg} / \mathrm{kg} /$ day $\mathrm{N}=12$ $1.0 \mathrm{mg} / \mathrm{kg} / \mathrm{day} \mathrm{N}=12$

Fig. 3 Lack of social approach to pro-social 50-kHz USV in female CPF-exposed rats. a Exemplary spectrograms showing $2 \mathrm{~s}$ of the pro-social 50kHz USV (upper panel) and time- and amplitude-matched white noise (lower panel) stimuli used in the playback assay. $\mathbf{b}$ Illustration of the radial maze used, with arms proximal to the active ultrasonic speaker shown in black, arms distal shown in white, and neutral arms shown in gray. $\mathbf{c}$ During the minute of USV playback, males of all exposure groups spent significantly more time on the arms proximal to the speaker compared to the distal arms. $\mathbf{d}$ In females, only the vehicle and $0.1 \mathrm{mg} / \mathrm{kg} /$ day CPF groups showed a significant preference for the proximal arms. Female rats exposed to $0.3 \mathrm{mg} / \mathrm{kg} /$ day or $1.0 \mathrm{mg} / \mathrm{kg} /$ day did not spend significantly more time on the proximal arms compared to the distal arms. Regardless of exposure, (e) all males and (f) females displayed similar patterns of locomotion in response to playback of 50-kHz USV. g All males and (h) females exhibited comparable levels of movement during the minute before and the minute of white noise. Data are mean + S.E.M. c, d: ${ }^{*} p<$ 0.05 , paired $t$ test, proximal vs. distal 

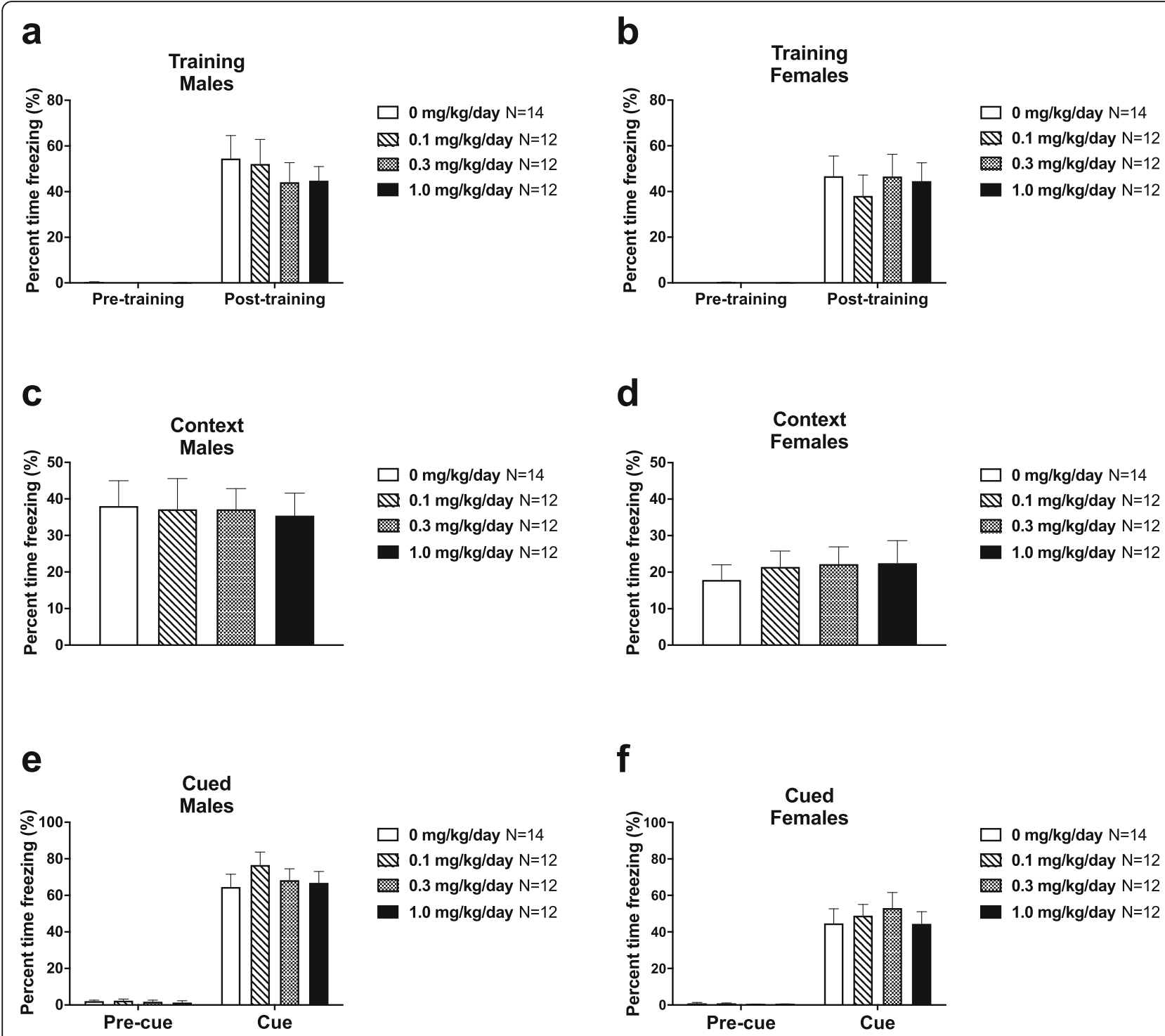

\section{f}
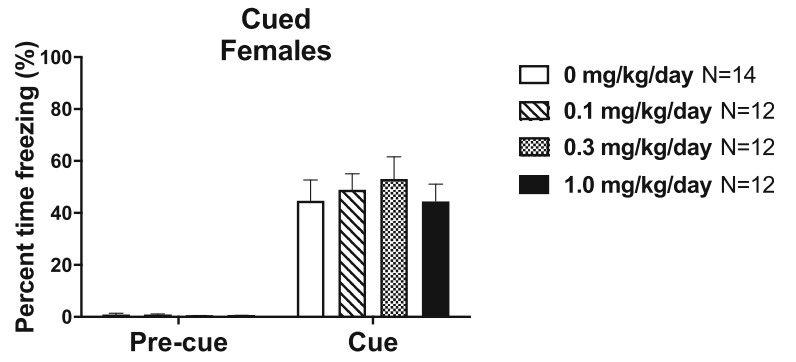

Fig. 4 Intact contextual and cued fear memory in rat pups exposed to CPF during early life. (a) Male and (b) female rats of all exposure groups exhibited typical levels of freezing following foot-shock training, $(\mathbf{c}, \mathbf{d})$ in the same context $24 \mathrm{~h}$ later, and $(\mathbf{e}, \mathbf{f})$ upon hearing the auditory cue in a new context $48 \mathrm{~h}$ after training. Data are mean + S.E.M

(females, pre-cue) $F_{(3,46)}=0.3858, p>0.05$; Fig. 4f (females, cue) $\left.F_{(3,46)}=0.2999, p>0.05\right)$.

\section{Neuroanatomical pathology at PND 35 following developmental CPF exposure}

Overall, the total brain volumes were not observed to be different between groups (1683 $\pm 101 \mathrm{~mm}^{3}$ for vehicle, $1649 \pm 51 \mathrm{~mm}^{3}$ for a CPF dosage of $0.1 \mathrm{mg} / \mathrm{kg}, 1675 \pm$ $123 \mathrm{~mm}^{3}$ for $0.3 \mathrm{mg} / \mathrm{kg}$, and $1662 \pm 68 \mathrm{~mm}^{3}$ for $1.0 \mathrm{mg} /$ $\mathrm{kg}$ ). A difference in total brain volume between vehicle and CPF exposure at $0.3 \mathrm{mg} / \mathrm{kg}$ of $-2.27 \%$ observed in the females was a mere one hundredth from significance $(p=0.06, q=0.22)$. There were no significant findings for any CPF exposure group nor for any sex when correcting for multiple comparisons. There was a trend toward a decrease in the hippocampal region $(-3.29 \%, p=$ 0.03, $q=0.22)$, which appeared to be localized to Ammon's Horn $(-3.52 \%, p=0.02, q=0.22)$. Additional trends toward a loss in volume were found in the fiber tracts $(-2.61 \%, p=0.03, q=0.22)$, with the strongest trends found in the fimbria $(-3.63 \%, p=0.02, q=0.22)$ and the cortical spinal tract $(-5.11 \%, p=0.01, q=0.22)$. Voxelwise comparisons also revealed no significant differences, but again interesting trends were seen in the female rats exposed to CPF at $0.3 \mathrm{mg} / \mathrm{kg}$ (Fig. 5). Interestingly, at the $0.3 \mathrm{mg} / \mathrm{kg}$ dosage, opposite effects are 


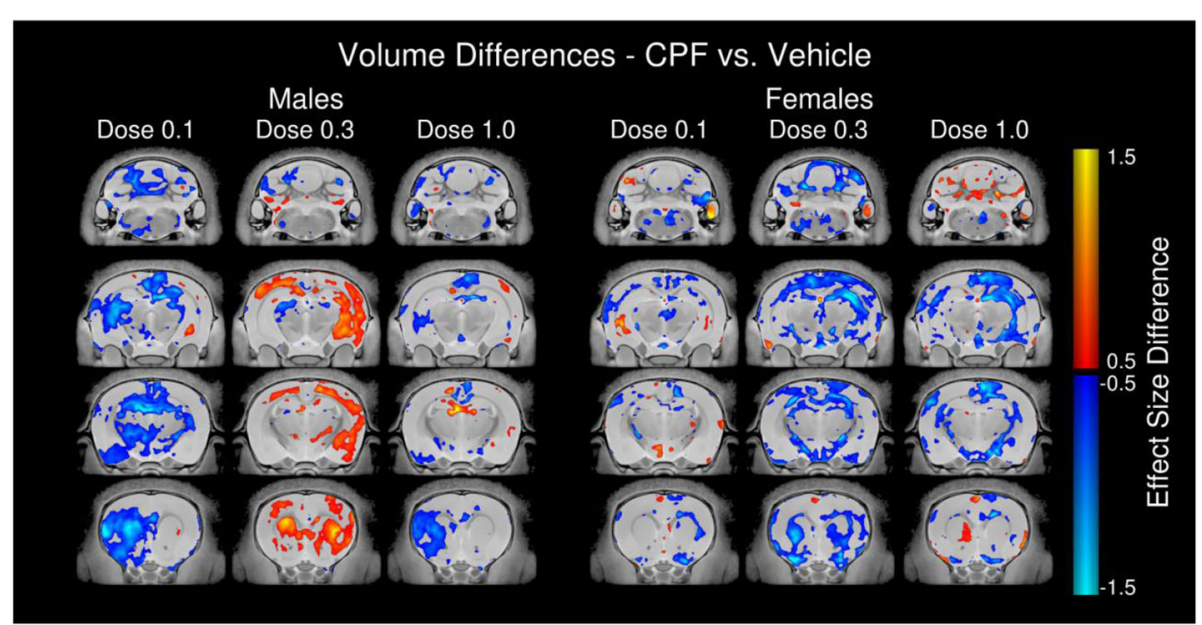

Fig. 5 Neuroanatomical pathology at PND 35 in rats exposed to CPF during early life. a Representative coronal slice series for males and females highlighting effect size differences in absolute brain volume $\left(\mathrm{mm}^{3}\right)$ between vehicle and $0.1 \mathrm{mg} / \mathrm{kg} / \mathrm{day}, 0.3 \mathrm{mg} / \mathrm{kg} / \mathrm{day}$, and $1.0 \mathrm{mg} / \mathrm{kg} / \mathrm{day} C P F$ exposure groups. Red-to-yellow coloration indicates areas that trended larger in CPF-exposed groups compared to vehicle and dark-to-light blue coloration indicates areas that were smaller in CPF-exposed groups compared to vehicle

seen in males versus females with males showing positive effect size differences and females showing negative effect size differences (Fig. 5).

\section{Normal brain and blood AChE activity following CPF exposure}

None of the three doses of CPF significantly altered the enzymatic activity of AChE in the brain (Fig. 6a $F_{(3,35)}=$ $0.1252, p>0.05$ ) or in the blood (Fig. $6 \mathrm{~b} F_{(3,34)}=0.2137$, $p>0.05)$.

\section{Discussion}

There is an extensive literature describing the developmental neurotoxicity of the OP pesticide chlorpyrifos (CPF). Epidemiological studies [8, 11-17], which provide compelling links between early life exposure to OPs and abnormal early cognitive development, may offer insights into the rising prevalence of neurodevelopmental disorders (NDDs). Epidemiological studies suggest that prenatal exposure to $\mathrm{CPF}$, particularly during the second or third trimester, is associated with significant mental and motor delays and with a clinical diagnosis of NDD, including ADHD and ASD [8, 16, 18, 20, 42]. To date, there have been fewer reports in preclinical mouse and rat models testing the hypothesis that developmental CPF exposure impairs behaviors relevant to the broad NDD phenotype. Herein, we report the initial behavioral and anatomical characterization of a rat model of developmental CPF exposure at doses that do not significantly inhibit acetylcholinesterase (AChE)

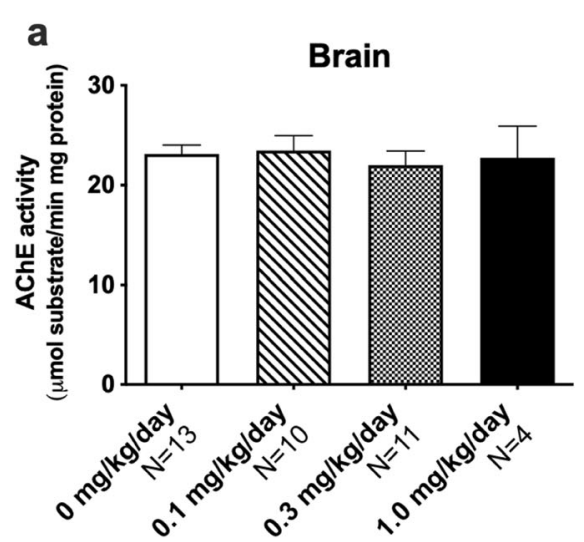

b

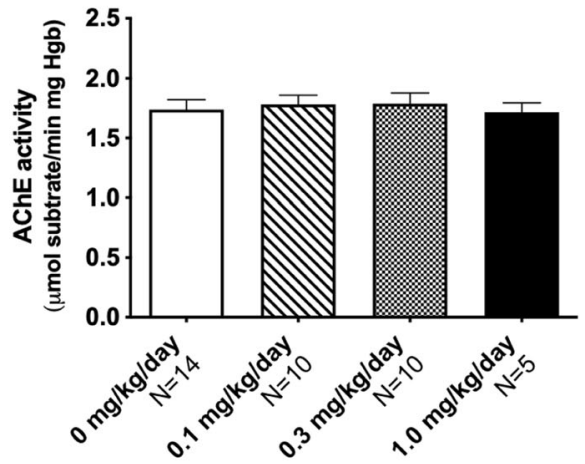

Fig. 6 Developmental CPF exposure did not significantly inhibit acetylcholinesterase (AChE). a Regardless of exposure group, all pups exposed to CPF on PND 1-4 showed normal AChE activity in the (a) brain and (b) blood at $1 \mathrm{~h}$ following the final dose on PND 4. Data include males and females and are mean + S.E.M 
activity. The most significant effect, reduced ultrasonic vocalization emission in pups, was observed in both sexes. We also discovered reduced social communication via a $50-\mathrm{kHz}$ USV playback assay, a USV call and behavioral response task that can only be performed/observed in rats, which supports our hypothesis because aberrant social communication aligns with the clinical profiles of many NDDs. Structural imaging illustrated a large number of changes in brain volume and a variety of neuroanatomical phenotypes. Collectively, this study identified unique NDD-relevant functional and anatomical phenotypes as preclinical outcomes in response to developmental CPF exposures that had no effects on AChE activity.

This is the first report of reduced ultrasonic vocalizations in rat pups following developmental CPF exposure. Ultrasonic vocalizations in pups are crucial signals that elicit maternal care, without which pups would not be able to thermoregulate or suckle [43]. Reduced USV communication has been discovered in many genetic rat models of NDD, including those with mutations in synaptic genes, such as Shank3, cellular housekeeping genes such as ubiquitin ligase Ube3a that causes Angelman syndrome, and the calcium channel gene Cacna1c [33, $34,44]$, as well as numerous genetic mouse models of NDD, including 16p11.2 deletion syndrome [45], the $\mathrm{Ca}(\mathrm{V}) 1.2 \mathrm{~L}$-type calcium channel gene that causes Timothy Syndrome [46], synaptic genes such as neuroligins [47], and high confidence ASD candidate genes, such as Tbx1 [48]. Reduced USV communication has also been reported in models of environmentally induced NDD phenotypes, including maternal immune activation [49], prenatal exposure to valproic acid [50, 51], and developmental exposure to traffic-related air pollution [35].

While we exposed rats to CPF during the first days of postnatal life, our findings are consistent with earlier literature showing that exposure to CPF during the gestational period resulted in altered behavioral and physical development in rodent pups in a sex-dependent manner. Venerosi and colleagues reported delayed somatic growth, reduced ultrasonic vocalizations, and increased latency to emit calls in male and female CD-1 mouse pups prenatally exposed to CPF [52], corroborating clinical reports in epidemiological studies [53]. Among mice exposed to the subtoxic doses of 1 and $3 \mathrm{mg} / \mathrm{kg} / \mathrm{d}$ CPF on PND 1-4 and PND 11-14, hyperactivity was observed only in those exposed to $3 \mathrm{mg} / \mathrm{kg} / \mathrm{d}$ CPF on PND 11-14 [24], which is consistent with our observation that the lower CPF doses tested in this study caused neither hypoactivity nor hyperactivity in rats in the open field task. However, in contrast to our findings, in the CD-1 strain mouse studies, the PND 1-4 exposure reduced brain cholinesterase activity by $25 \%$. Studies of rats injected with $1 \mathrm{mg} / \mathrm{kg} / \mathrm{d}$ CPF on PND 1-4 have also reported significantly reduced $\mathrm{AChE}$ activity in the brain ranging from 20 to $60 \%$ depending on sex and the interval between the last injection of CPF and the collection of tissue for analyses $[22,54]$. The key differences between our study and the two earlier rat studies was the vehicle used for CPF dosing: we used a coconut oil preparation whereas the previously published rat studies, and the mouse study, used DMSO. Pharmacokinetic studies in adult rats have shown that subcutaneous administration of CPF in corn oil resulted in faster absorption and metabolism of CPF compared to a subcutaneous administration of CPF in DMSO [55]. Whether this is the reason why we did not see a significant inhibition of AChE whereas other studies have despite using the same doses over the same developmental ages in the same rat strain has yet to be determined.

Exposure to CPF at $1 \mathrm{mg} / \mathrm{kg}$ during early postnatal life elicited deficits in reflex righting and geotaxis behavior in female rat pups [22]. This was also observed recently in Harlan-derived B6 mice exposed to $2.5 \mathrm{mg} / \mathrm{kg}$ of CPF on gestational days 12-15 [23]. Exposure to CPF at 1.5 $\mathrm{mg} / \mathrm{kg}$ in early postnatal life reduced body weight in male Sprague-Dawley rats [28]. In contrast, we observed no effect of the CPF doses on the neonatal reflexes of negative geotaxis and circle traverse.

We discovered impaired juvenile behavioral responses to the playback of $50-\mathrm{kHz}$ USV, a positive affiliative social contact call associated with play and social interactions. Reductions in playback social approach have been observed in other genetic rat models of NDD such as Shank3, Ube3a, and Cacna1c [33, 34, 44]. Juvenile social approach during playback is a bidirectional social communication behavior commonly studied in rats rather than mice as most reports that use choice playback in mice use sexual mating calls to elicit behavior [56, 57] and because inbred or congenic B6J mice cannot hear in the frequency range of ultrasonic vocalizations $[58,59]$. We observed that female rats exposed to CPF at 0.3 or $1.0 \mathrm{mg} / \mathrm{kg}$ have a deficit in the key social approach behavior following a playful $50-\mathrm{kHz}$ USV. This effect is not a consequence of deficits in psychomotor activation, motor abilities, or hearing. This conclusion is based on no evidence of motor impairments in the open field, pre-training or pre-cue activity in fear conditioning, and the total distance traversed following presentation of 50$\mathrm{kHz}$ USV, a key control metric for the social playback assay. These observations suggest the arousal-evoking component of the playback is intact but that the deficit is specific to the social approach parameter of the assay. This could be due to multiple reasons including the CPF-exposed rats not being able to localize the sound source, the CPF-exposed rats having less dopaminergicmediated motivation for social reward, and/or the CPFexposed rats not being able to understand the 
communicative function of the pro-social $50-\mathrm{kHz}$ USV. Differentiating between the various possible explanations will require future experiments beyond the scope of this initial generation of the rat model [60-62].

Our observations of the effects of developmental CPF exposure are novel because they are among the first reports of NDD-relevant phenotypes in a socially sophisticated rodent species, the rat. Our findings extend earlier literature of unusual social behavior elicited by developmental CPF exposure in mouse models with a wide variety of doses and exposure windows. Mouse research showed that neonatal CPF exposure $(3 \mathrm{mg} / \mathrm{kg})$ increased sexual social soliciting behaviors, specifically aggressive behaviors in mice exposed to a subtoxic dose of CPF during a different early life period (PND 11-14) [24]. Adult male mice exposed to CPF prenatally $(6 \mathrm{mg} / \mathrm{kg})$ or postnatally $(3 \mathrm{mg} / \mathrm{kg})$ exhibited increased aggressive behaviors during a social dyadic interaction test [25]. The increase in aggressive behaviors in male mice at an age when affiliative behaviors should be prevalent suggests a deviation from the species-typical pattern of social behavior [63]. Moreover, gestational and neonatal exposure to $\mathrm{CPF}$ resulted in impaired nest building and maternal aggression in lactating female mice, indicating impaired maternal behavior [64, 65]. Mounting evidence suggests that CPF could disrupt the endocrine system and adversely affect social behavior in a sexually dimorphic manner, as extensively reviewed elsewhere [66]. A recent study reported reductions in social preference ratio in Harlan-derived B6 mice of both sexes exposed to 2.5 $\mathrm{mg} / \mathrm{kg}$ or $5.0 \mathrm{mg} / \mathrm{kg}$ of CPF on gestational days $12-15$ [67]. Our findings contrast with a report of increased social play in juvenile rats using CPF doses of less than 1.0 $\mathrm{mg} / \mathrm{kg}$ [68]; however, the dosing in our study was across PND 1-4 while that exposure paradigm started at PND 10 and lasted for 7 days, emphasizing the critical effect of timing in behavioral toxicology. Detailed examination of reciprocal social play interactions is planned for subsequent studies.

This is also the first report to utilize ex vivo MRI to examine broad effects of developmental CPF exposure. Neuroanatomically, the CPF dosages had no significant effects on the mesoscopic brain structure of the rats. There were interesting trends at the 0.3 $\mathrm{mg} / \mathrm{kg}$ dose, in particular, the divergent direction of the structural findings in males (increased volume) and females (volumetric reductions). Typically, in neuroimaging studies of genetic mouse models, significant differences in relative regional volumes are usually found in about $65 \%$ of cases [69]. These types of studies are powered at $80 \%$ which should typically find regional differences in the mouse at $3-5 \%$, which is consistent with some of the differences at $0.3 \mathrm{mg} /$ $\mathrm{kg}$ dose. Powered at this level, our studies tend to be more sensitive to widespread changes rather than focal ones, which could explain our observation of "trends" in this work. Additionally, it is possible that there is increased variability in the rat versus mouse due to the substantially more variable genetic background than in the mouse, but this remains to be tested for CPF exposures specifically and is only beginning to be compared in genetic rat models of NDDs. It should also be noted that the findings here do not indicate that there are no structural differences due to CPF, only that no significant changes are detectable at the mesoscopic resolution of the MRI. Going forward, we will perform more regionally targeted neuroanatomy using the strongest trending areas observed in this study.

We did not observe effects of developmental CPF exposure on motor activity. While others have observed changes, those effects were found at higher dose exposures and/or in mice. For example, pre- and postnatal CPF exposure (6 or $3 \mathrm{mg} / \mathrm{kg}$, respectively) markedly increased locomotor activity in adult male mice tested in the open field [25]. These results corroborated the finding of decreased habituation rate in rats exposed to 1.0 $\mathrm{mg} / \mathrm{kg}$ CPF during the later postnatal period [29]. However, habituation rate on a radial maze is not the same metric as assessing locomotion in a novel arena. Exposure to $\mathrm{CPF}$ at $1 \mathrm{mg} / \mathrm{kg}$ during early postnatal life reduced locomotor activity and rearing in adolescent SpragueDawley male rats [22]. However, rats postnatally exposed to diazinon $(0.5$ and $2 \mathrm{mg} / \mathrm{kg})$, another OP pesticide, exhibited normal locomotor activity and a normal habituation pattern in a $1 \mathrm{~h}$ figure- 8 locomotor activity test [70]. Taken together, there is a lack of consistency and corroboration suggesting that locomotor activity is not a sensitive, reproducible, and rigorous endpoint for lowlevel OP exposures in preclinical rodent models. Adverse effects on performance are often observed in a single laboratory, and follow-up literature is unable to reproduce or delineate cognitive impairments from motoric dysfunction [71, 72]. Future directions intended to comprehensively assess motor behavior with a specific behavioral battery that includes gait, balance, coordination, velocity, temporal and spatial dynamic metrics over rudimentary activity, and/or habituation will lead to improved translational value. This will allow for direct comparisons to humans using devices such as pressure sensitive mats, electromyographic recordings, and wrist or ankle monitors that measure activity/balance.

We also did not observe any deficits in cued and contextual fear conditioning, a classic yet simplistic assay of learning and memory. Earlier studies found that juvenile rats exposed to doses of CPF ( 0.3 or $7.0 \mathrm{mg} / \mathrm{kg}$ ) early in life (PND 7, 11, and 15) exhibited spatial learning deficits in the Morris water maze [27]. A second cohort of 
juvenile rats exposed to $\mathrm{CPF}(0.3$ and $7.0 \mathrm{mg} / \mathrm{kg}$ ) at a later age (PND 22 and 26) exhibited similar impairments [27]. Neonatal CPF exposure $(5 \mathrm{mg} / \mathrm{kg})$ on PND 1-4, but not on PND 5-11, impaired radial-arm maze choice accuracy during the initial phase of training when the test situation is novel or cholinergic inputs are required [29]. As these assays measure substantially different components of learning and memory, we are cautious to state there is a contrast between our findings and that of these earlier reports. As most literature points to a significant effect of CPF on learning and memory, we attribute differences between previous results and our lack of this finding in fear conditioning to the lack of task sensitivity as well as varying doses and timing of exposures. Future directions intend to comprehensively assess the adverse effects of developmental exposure to CPF on learning and memory with improved translational value by using computerized touchscreen technology, which will hopefully unify the current literature, as each earlier report measured a different parameter or form of learning and memory.

A key question is the relevance of the doses used in this study to human exposures. The estimated average daily combined intake of chlorpyrifos and chlorpyrifosmethyl for infants ranges from $0.003 \mu \mathrm{g} / \mathrm{kg} /$ day [73] to $0.018 \mathrm{ug} / \mathrm{kg} /$ day [7]. While these levels are many orders of magnitude lower than the doses administered to postnatal rats in this study, it is critical to remember that the human data reflect estimated average daily exposures and do not take into account exposures during periods of active pesticide exposure in the home, school, or nearby agricultural fields. A more relevant comparison is CPF levels in human cord blood at birth, which range from $3.7 \mathrm{pg} / \mathrm{g}$ [16] to $>6.17 \mathrm{pg} / \mathrm{g}$ [74]. The peak level of CPF in the blood of PND 5 rats dosed with CPF at $1 \mathrm{mg} / \mathrm{kg}$ in DMSO (s.c.) was approximately $9 \mathrm{ng} / \mathrm{ml}$ [75]. While these data imply that our dosing paradigm likely resulted in CPF levels in the postnatal rats that are 2-3 orders of magnitude higher than are detected in human neonates, direct comparison of these levels to determine relevance is complicated by the observation that rat blood contains high levels of circulating carboxyesterases, which metabolically inactivate organophosphorus (OP) insecticides, such as CPF, whereas humans have low levels of these enzymes [74]. Thus, the percentage of any CPF dose that reaches the brain is likely to be significantly lower in rats than in humans.

Biological mechanisms of OP toxicity are complex. The canonical mechanism of OP neurotoxicity is inhibition of AChE, which hydrolyzes acetylcholine. More importantly, and most relevant to the present work, it is widely posited that developmental OP neurotoxicity involves mechanisms other than or in addition to AChE inhibition, as recently reviewed [76, 77]. The robust behavioral findings reported in these animals exposed to CPF at doses that have no significant effect on blood or brain AChE clearly support non-cholinergic mechanisms as contributing to effects that are translationally relevant for NDDs. Further biochemical assays using this exposure paradigm must be evaluated in future follow-up studies.

\section{Conclusions}

Collectively, our results indicate that early life exposure to the OP pesticide CPF leads to behavioral and some possible neuroanatomical differences in rats that are highly relevant to NDDs. Interestingly, the effects of $\mathrm{CPF}$ we observed were strong, observed at multiple timepoints of development, in both sexes, and at doses that did not inhibit AChE activity. By developing and utilizing a novel rat model of developmental CPF exposure, which leverages the sophisticated vocal communication system of rats, we characterized the effect of environmentally relevant $\mathrm{CPF}$ exposures on a range of behaviors and were able to detect impaired social communication in pups and juveniles. Critically, these effects occurred in the absence of AChE inhibition, which is the endpoint used to regulate $\mathrm{OP}$ exposures to protect human health.

The public health implications of these results are significant, as pesticides continue to be widely used resulting in widespread human exposures. With the laws regarding pesticide application currently under debate, this work provides timely and much needed experimental evidence to inform future policy decisions.

\section{Supplementary Information}

The online version contains supplementary material available at https://doi. org/10.1186/s11689-020-09342-1.

Additional file 1: Supplementary Fig S1. Reduced USV emission in rat pups exposed to CPF during early life. a Male pups exposed to CPF emitted normal numbers of USV on PND 8 compared to vehicle controls while b exposure to $1.0 \mathrm{mg} / \mathrm{kg} /$ day CPF in females resulted in reduced USV emission relative to controls. Data are mean + S.E.M. ${ }^{*} p<0.05$, oneway ANOVA, Holm-Sidak's multiple comparisons post hoc. Supplementary Fig S2. No effect of early life CPF exposure on developmental milestone achievement. $\mathbf{a}, \mathbf{b}$ Performance on the negative geotaxis and $\mathbf{c}, \mathbf{d}$ circle traverse tasks did not differ between exposure groups for males or females, respectively. Data are mean \pm S.E.M.

\section{Acknowledgements}

There are no acknowledgements other than the funding sources already mentioned.

\section{Authors' contributions}

$E L B, D A B, J E, P J L$, and JLS contributed to the study conception and design. ELB, TMC, DAB, JKR, MC, JE, and JPL contributed to the acquisition of the data. ELB, TMC, DAB, JE, JPL, MW, PJL, and JLS contributed to the analysis and interpretation of the data. ELB, DAB, JE, PJL, and JLS made significant contributions to the manuscript. All authors read and approved the final manuscript. 


\section{Funding}

This project used core facilities and was supported by a pilot grant from the UC Davis MIND Institute Intellectual and Developmental Disabilities Research Center (IDDRC; U54 HD079125). This work was also supported by a pilot grant from the UC Davis Environmental Health Sciences Center (P30 ES023513)

\section{Availability of data and materials}

Datasets available from corresponding author upon reasonable request.

\section{Ethics approval and consent to participate}

This work was conducted in accordance with the guidelines set forth by the University of California Davis Institutional Animal Care and Use Committee.

\section{Consent for publication}

Not applicable.

\section{Competing interests}

Authors declare no competing interests.

\section{Author details}

'MIND Institute and Department of Psychiatry and Behavioral Sciences, University of California Davis School of Medicine, Sacramento, CA, USA. ${ }^{2}$ MIND Institute and Department of Molecular Biosciences, University of California Davis School of Veterinary Medicine, Davis, CA, USA. ${ }^{3}$ Mouse Imaging Centre, Toronto Centre for Phenogenomics, The Hospital for Sick Children, Toronto, Ontario, Canada. ${ }^{4}$ Wellcome Centre for Integrative Neuroimaging, The University of Oxford, Oxford, UK. ${ }^{5}$ Behavioral Neuroscience, Experimental and Biological Psychology, Philipps University of Marburg, Marburg, Germany. 'Laboratory for Behavioral Neuroscience, Department of Biology, Faculty of Science, University of Southern Denmark, Campusvej 55, DK-5230 Odense M, Denmark.

\section{Received: 13 February 2020 Accepted: 13 November 2020} Published online: 16 December 2020

\section{References}

1. Carvalho F. Agriculture, pesticides, food security and food safety. Environ Sci Policy. 2006;9(7-8):685-92.

2. Dich J, Zahm SH, Hanberg A, Adami HO. Pesticides and cancer. Cancer Causes Control. 1997;8:420-43. https://doi.org/10.1023/a:1018413522959.

3. Hertz-Picciotto I, et al. Organophosphate exposures during pregnancy and child neurodevelopment: recommendations for essential policy reforms. Plos Med. 2018a;15:e1002671. https://doi.org/10.1371/journal.pmed.1002671.

4. Hertz-Picciotto I, Schmidt RJ, Krakowiak P. Understanding environmental contributions to autism: causal concepts and the state of science. Autism Res. 2018b;11:554-86. https://doi.org/10.1002/aur.1938.

5. Hertz-Picciotto I, et al. A prospective study of environmental exposures and early biomarkers in autism spectrum disorder: design, protocols, and preliminary data from the MARBLES Study. Environ Health Perspect. 2018c; 126:117004. https://doi.org/10.1289/EHP535.

6. (EPA), E.P.A. (2000). Revised risk assessment for chlorpyrifos.

7. Eaton $\mathrm{DL}$, et al. Review of the toxicology of chlorpyrifos with an emphasis on human exposure and neurodevelopment. Crit Rev Toxicol. 2008;38(Suppl 2):1-125. https://doi.org/10.1080/10408440802272158.

8. Shelton JF, Hertz-Picciotto I, Pessah IN. Tipping the balance of autism risk: potential mechanisms linking pesticides and autism. Environ Health Perspect. 2012;120:944-51. https://doi.org/10.1289/ehp.1104553.

9. (EPA), E.P.A, Grube A, Donaldson D, Kiely T, Wu L. In: (EPA), E.P.A, editor. Pesticides industry sales and usage: 2006 and 2007 Market Estimates; 2011.

10. Solomon KR, Williams WM, Mackay D, Purdy J, Giddings JM, Giesy JP. Properties and uses of chlorpyrifos in the United States. Revi Environ Contam Toxicol. 2014;231:13-34. https:/doi.org/10.1007/978-3-319-03865-0_2.

11. Bouchard MF, Bellinger DC, Wright RO, Weisskopf MG. Attention-deficit/ hyperactivity disorder and urinary metabolites of organophosphate pesticides. Pediatrics. 2010;125:e1270-7. https://doi.org/10.1542/peds.20093058.

12. Bouchard MF, et al. Prenatal exposure to organophosphate pesticides and IQ in 7-year old children. Environ Health Perspect. 2011. https://doi.org/10. 1289/ehp.1003185.
13. Engel SM, et al. Prenatal organophosphate metabolite and organochlorine levels and performance on the Brazelton Neonatal Behavioral Assessment Scale in a multiethnic pregnancy cohort. Am J Epidemiol. 2007;165:1397404. https://doi.org/10.1093/aje/kwm029.

14. Engel SM, et al. Prenatal exposure to organophosphates, paraoxonase 1, and cognitive development in childhood. Environ Health Perspect. 2011. https://doi.org/10.1289/ehp.1003183.

15. Furlong MA, Engel SM, Barr DB, Wolff MS. Prenatal exposure to organophosphate pesticides and reciprocal social behavior in childhood. Environ Int. 2014;70:125-31. https://doi.org/10.1016/j.envint.2014.05.011.

16. Rauh $V$, et al. 7-year neurodevelopmental scores and prenatal exposure to chlorpyrifos, a common agricultural pesticide. Environ Health Perspect. 2011 https://doi.org/10.1289/ehp.1003160.

17. Rauh VA, et al. Impact of prenatal chlorpyrifos exposure on neurodevelopment in the first 3 years of life among inner-city children. Pediatrics. 2006;118:e1845-59. https://doi.org/10.1542/peds.2006-0338.

18. Shelton JF, et al. Neurodevelopmental disorders and prenatal residential proximity to agricultural pesticides: the CHARGE Study. Environ Health Perspect. 2014:122:1103-9. https://doi.org/10.1289/ehp.1307044.

19. Young JG, et al. Association between in utero organophosphate pesticide exposure and abnormal reflexes in neonates. Neurotoxicology. 2005;26:199_ 209. https://doi.org/10.1016/j.neuro.2004.10.004.

20. Rauh VA, et al. Brain anomalies in children exposed prenatally to a common organophosphate pesticide. Proc Natl Acad Sci U S A. 2012;109:7871-6. https://doi.org/10.1073/pnas.1203396109.

21. Pelch KE, Bolden AL, Kwiatkowski CF. Environmental chemicals and autism: a scoping review of the human and animal research. Environ Health Perspect. 2019;127:46001. https://doi.org/10.1289/EHP4386.

22. Dam K, Seidler FJ, Slotkin TA. Chlorpyrifos exposure during a critical neonatal period elicits gender-selective deficits in the development of coordination skills and locomotor activity. Brain Res Dev Brain Res. 2000;121: 179-87.

23. Lan A, Kalimian M, Amram B, Kofman O. Prenatal chlorpyrifos leads to autism-like deficits in C57Bl6/J mice. Environ Health. 2017;16:43. https://doi. org/10.1186/s12940-017-0251-3.

24. Ricceri L, et al. Developmental exposure to chlorpyrifos alters reactivity to environmental and social cues in adolescent mice. Toxicol Appl Pharmacol. 2003:191:189-201.

25. Ricceri L, et al. Developmental neurotoxicity of organophosphorous pesticides: fetal and neonatal exposure to chlorpyrifos alters sex-specific behaviors at adulthood in mice. Toxicol Sci. 2006;93:105-13. https://doi.org/ 10.1093/toxsci/kfl032.

26. Aldridge JE, Levin ED, Seidler FJ, Slotkin TA. Developmental exposure of rats to chlorpyrifos leads to behavioral alterations in adulthood, involving serotonergic mechanisms and resembling animal models of depression. Environ Health Perspect. 2005;113:527-31.

27. Jett DA, Navoa RV, Beckles RA, McLemore GL. Cognitive function and cholinergic neurochemistry in weanling rats exposed to chlorpyrifos. Toxicol Appl Pharmacol. 2001;174:89-98. https://doi.org/10.1006/taap.2001.9198.

28. Johnson FO, Chambers JE, Nail CA, Givaruangsawat S, Carr RL. Developmental chlorpyrifos and methyl parathion exposure alters radial-arm maze performance in juvenile and adult rats. Toxicol Sci. 2009;109:132-42. https://doi.org/10.1093/toxsci/kfp053.

29. Levin ED, Addy N, Nakajima A, Christopher NC, Seidler FJ, Slotkin TA. Persistent behavioral consequences of neonatal chlorpyrifos exposure in rats. Brain Res Dev Brain Res. 2001;130:83-9.

30. Hofer MA. Multiple regulators of ultrasonic vocalization in the infant rat. Psychoneuroendocrinology. 1996;21:203-17.

31. Hofer, M.A., H.N. Shair, S.A. Brunelli (2002). Ultrasonic vocalizations in rat and mouse pups. Current protocols in neuroscience/editorial board, Jacqueline N Crawley [et al] Chapter 8, Unit 814 doi:10.1002/0471142301.ns0814s17.

32. Wöhr M, Schwarting RK. Maternal care, isolation-induced infant ultrasonic calling, and their relations to adult anxiety-related behavior in the rat. Behav Neurosci. 2008;122:310-30. https://doi.org/10.1037/07357044.122.2.310.

33. Berg EL, et al. Developmental social communication deficits in the Shank3 rat model of Phelan-Mcdermid syndrome and autism spectrum disorder. Autism Res. 2018;11:587-601. https://doi.org/10.1002/aur.1925.

34. Berg EL, et al. Translational outcomes in a full gene deletion of ubiquitin protein ligase E3A rat model of Angelman syndrome. Transl Psychiatry. 2020;10. https://doi.org/10.1038/s41398-020-0720-2. 
35. Berg EL, Pedersen LR, Pride MC, Petkova SP, Patten KT, Valenzuela AE, et al. Developmental exposure to near roadway pollution produces behavioral phenotypes relevant to neurodevelopmental disorders in juvenile rats. Transl Psychiatry. 2020;10(1):1-6. https://doi.org/10.1038/s41398-020-00978-0.

36. Cahill LS, et al. Preparation of fixed mouse brains for MRI. Neurolmage. 2012;60:933-9. https://doi.org/10.1016/j.neuroimage.2012.01.100.

37. Gompers AL, et al. Germline Chd8 haploinsufficiency alters brain development in mouse. Nat Neurosci. 2017;20:1062-73. https://doi.org/10. 1038/nn.4592

38. Genovese CR, Lazar NA, Nichols T. Thresholding of statistical maps in functional neuroimaging using the false discovery rate. Neurolmage. 2002; 15:870-8. https://doi.org/10.1006/nimg.2001.1037.

39. Ellman GL, Courtney KD, Andres V Jr, Featherstone RM. A new and rapid colorimetric determination of acetylcholinesterase activity. Biochem Pharmacol. 1961;7(2):88-95. https://doi.org/10.1016/0006-2952(61)90145-9.

40. Bushnell PJ, Moser VC, Samsam TE. Comparing cognitive and screening tests for neurotoxicity. Effects of acute chlorpyrifos on visual signal detection and a neurobehavioral test battery in rats. Neurotoxicol Teratol. 2001;23:33-44.

41. Moser VC. Comparisons of the acute effects of cholinesterase inhibitors using a neurobehavioral screening battery in rats. Neurotoxicol Teratol. 1995; 17:617-25.

42. Whyatt RM, et al. Biomarkers in assessing residential insecticide exposures during pregnancy and effects on fetal growth. Toxicol Appl Pharmacol. 2005;206:246-54. https://doi.org/10.1016/j.taap.2004.11.027.

43. Brudzynski S. Handbook of mammalian vocalization: an integrative neuroscience approach. Netherlands: Academic Press; 2009.

44. Kisko TM, et al. Cacna1c haploinsufficiency leads to pro-social $50-\mathrm{kHz}$ ultrasonic communication deficits in rats. Dis Models Mech. 2018;11. https:// doi.org/10.1242/dmm.034116.

45. Yang M, Lewis FC, Sarvi MS, Foley GM, Crawley JN. 16p11.2 Deletion mice display cognitive deficits in touchscreen learning and novelty recognition tasks. Learn Memory. 2015;22:622-32. https://doi.org/10.1101//m.039602.115.

46. Bader PL, et al. Mouse model of Timothy syndrome recapitulates triad of autistic traits. Proc Natl Acad Sci U S A. 2011;108:15432-7. https://doi.org/10. 1073/pnas.1112667108.

47. Wöhr M, et al. Developmental delays and reduced pup ultrasonic vocalizations but normal sociability in mice lacking the postsynaptic cell adhesion protein neuroligin2. Behav Brain Res. 2013;251:50-64. https://doi. org/10.1016/j.bbr.2012.07.024.

48. Hiramoto T, et al. Tbx1: identification of a 22q11.2 gene as a risk factor for autism spectrum disorder in a mouse model. Hum Mol Genet. 2011;20: 4775-85. https://doi.org/10.1093/hmg/ddr404.

49. Schwartzer JJ, Careaga M, Onore CE, Rushakoff JA, Berman RF, Ashwood P. Maternal immune activation and strain specific interactions in the development of autism-like behaviors in mice. Translational psychiatry. 2013; 3:e240. https://doi.org/10.1038/tp.2013.16

50. Moldrich RX, et al. Inhibition of histone deacetylase in utero causes sociability deficits in postnatal mice. Behav Brain Res. 2013;257:253-64. https://doi.org/10.1016/j.bbr.2013.09.049.

51. Tartaglione AM, et al. Early behavioral alterations and increased expression of endogenous retroviruses are inherited across generations in mice prenatally exposed to valproic acid. Mol Neurobiol. 2019;56:3736-50. https:// doi.org/10.1007/s12035-018-1328-x.

52. Venerosi A, Ricceri L, Scattoni ML, Calamandrei G. Prenatal chlorpyrifos exposure alters motor behavior and ultrasonic vocalization in CD-1 mouse pups. Environ Health. 2009:8:12. https://doi.org/10.1186/1476-069X-8-12.

53. Whyatt RM, et al. Prenatal insecticide exposures and birth weight and length among an urban minority cohort. Environ Health Perspect. 2004;112: 1125-32.

54. Song X, Seidler FJ, Saleh JL, Zhang J, Padilla S, Slotkin TA. Cellular mechanisms for developmental toxicity of chlorpyrifos: targeting the adenylyl cyclase signaling cascade. Toxicol Appl Pharmacol. 1997;145:15874. https://doi.org/10.1006/taap.1997.8171.

55. Smith JN, Campbell JA, Busby-Hjerpe AL, Lee S, Poet TS, Barr DB, Timchalk C. Comparative chlorpyrifos pharmacokinetics via multiple routes of exposure and vehicles of administration in the adult rat. Toxicology. 2009; 261:47-58. https://doi.org/10.1016/j.tox.2009.04.041.

56. Chabout J, Sarkar A, Dunson DB, Jarvis ED. Male mice song syntax depends on social contexts and influences female preferences. Front Behav Neurosci. 2015;9:76. https://doi.org/10.3389/fnbeh.2015.00076.
57. Hammerschmidt K, Radyushkin K, Ehrenreich H, Fischer J. Female mice respond to male ultrasonic 'songs' with approach behaviour. Biol Lett. 2009; 5:589-92. https://doi.org/10.1098/rsbl.2009.0317.

58. Hammerschmidt K, Reisinger E, Westekemper K, Ehrenreich L, Strenzke N, Fischer J. Mice do not require auditory input for the normal development of their ultrasonic vocalizations. BMC Neurosci. 2012;13:40. https://doi.org/ 10.1186/1471-2202-13-40.

59. Portfors CV, Perkel DJ. The role of ultrasonic vocalizations in mouse communication. Curr Opin Neurobiol. 2014;28:115-20. https://doi.org/10. 1016/j.conb.2014.07.002

60. Seffer D, Schwarting RK, Wöhr M. Pro-social ultrasonic communication in rats: insights from playback studies. J Neurosci Methods. 2014. https://doi. org/10.1016/j.jneumeth.2014.01.023.

61. Wöhr M, Schwarting RK. Ultrasonic communication in rats: can playback of 50-kHz calls induce approach behavior? Plos One. 2007;2:e1365. https://doi. org/10.1371/journal.pone.0001365.

62. Wöhr M, Seffer D, Schwarting RK. Studying socio-affective communication in rats through playback of ultrasonic vocalizations. Curr Protoc Neurosci. 2016;75:8 35 1-17. https://doi.org/10.1002/cpns.7.

63. Terranova ML, Laviola G, Alleva E. Ontogeny of amicable social behavior in the mouse: gender differences and ongoing isolation outcomes. Dev Psychobiol. 1993;26:467-81. https://doi.org/10.1002/dev.420260805.

64. Venerosi A, Cutuli D, Colonnello V, Cardona D, Ricceri L, Calamandrei G. Neonatal exposure to chlorpyrifos affects maternal responses and maternal aggression of female mice in adulthood. Neurotoxicol Teratol. 2008;30:46874. https://doi.org/10.1016/j.ntt.2008.07.002.

65. Venerosi A, Ricceri L, Rungi A, Sanghez V, Calamandrei G. Gestational exposure to the organophosphate chlorpyrifos alters social-emotional behaviour and impairs responsiveness to the serotonin transporter inhibitor fluvoxamine in mice. Psychopharmacology. 2010;208:99-107. https://doi. org/10.1007/s00213-009-1713-2.

66. Venerosi A, Ricceri L, Tait S, Calamandrei G. Sex dimorphic behaviors as markers of neuroendocrine disruption by environmental chemicals: the case of chlorpyrifos. Neurotoxicology. 2012;33:1420-6. https://doi.org/10.1016/j. neuro.2012.08.009.

67. Lan A, Stein D, Portillo M, Toiber D, Kofman O. Impaired innate and conditioned social behavior in adult C57B/6/J mice prenatally exposed to chlorpyrifos. Behav Brain Functions. 2019;15:2. https://doi.org/10.1186/ s12993-019-0153-3.

68. Carr RL, et al. Inhibition of fatty acid amide hydrolase by chlorpyrifos in juvenile rats results in altered exploratory and social behavior as adolescents. Neurotoxicology. 2020;77:127-36. https://doi.org/10.1016/j. neuro.2020.01.002.

69. Ellegood J, et al. Clustering autism: using neuroanatomical differences in 26 mouse models to gain insight into the heterogeneity. Mol Psychiatry. 2015; 20:118-25. https://doi.org/10.1038/mp.2014.98.

70. Timofeeva OA, Roegge CS, Seidler FJ, Slotkin TA, Levin ED. Persistent cognitive alterations in rats after early postnatal exposure to low doses of the organophosphate pesticide, diazinon. Neurotoxicol Teratol. 2008;30:3845. https://doi.org/10.1016/j.ntt.2007.10.002.

71. Sukoff Rizzo SJ, Anderson LC, Green TL, McGarr T, Wells G, Winter SS. Assessing healthspan and lifespan measures in aging mice: optimization of testing protocols, replicability, and rater reliability. Curr Protoc Mouse Biol. 2018;8:e45. https://doi.org/10.1002/cpmo.45.

72. Sukoff Rizzo SJ, Silverman JL. Methodological considerations for optimizing and validating behavioral assays. Curr Protoc Mouse Biol. 2016;6:364-79. https://doi.org/10.1002/cpmo.17.

73. Morgan MK, Sheldon LS, Croghan CW, Jones PA, Robertson GL, Chuang JC, Wilson NK, Lyu CW. Exposures of preschool children to chlorpyrifos and its degradation product 3, 5, 6-trichloro-2-pyridinol in their everyday environments. J Exposure Sci Environ Epidemiol. 2005;15:297309.

74. Burke RD, et al. Developmental neurotoxicity of the organophosphorus insecticide chlorpyrifos: from clinical findings to preclinical models and potential mechanisms. J Neurochem. 2017;142(Suppl 2):162-77. https://doi. org/10.1111/jnc.14077.

75. Marty MS, Domoradzki JY, Hansen SC, Timchalk C, Bartels MJ, Mattsson JL. The effect of route, vehicle, and divided doses on the pharmacokinetics of chlorpyrifos and its metabolite trichloropyridinol in neonatal SpragueDawley rats. Toxicol Sci. 2007;100:360-73. https://doi.org/10.1093/toxsci/ kfm239. 
76. Guignet M, Lein PJ. Organophosphates. In: Advances in neurotoxicology: role of inflammation in environmental neurotoxicity. In: Aschner $\mathrm{M}$, Costa LG, editors. Advances in Neurotoxicology: Role of Inflammation in Environmental Neurotoxicity. Cambridge, MA: Academic Press; 2019. p. 3579 .

77. Voorhees JR, Rohlman DS, Lein PJ, Pieper AA. Neurotoxicity in preclinical models of occupational exposure to organophosphorus compounds. Front Neurosci. 2016;10:590. https://doi.org/10.3389/fnins.2016.00590.

\section{Publisher's Note}

Springer Nature remains neutral with regard to jurisdictional claims in published maps and institutional affiliations.

Ready to submit your research? Choose BMC and benefit from:

- fast, convenient online submission

- thorough peer review by experienced researchers in your field

- rapid publication on acceptance

- support for research data, including large and complex data types

- gold Open Access which fosters wider collaboration and increased citations

- maximum visibility for your research: over $100 \mathrm{M}$ website views per year

At $\mathrm{BMC}$, research is always in progress.

Learn more biomedcentral.com/submissions 